\title{
PROSEDUR PEMBERIAN KREDIT KPR PADA PT. BANK TABUNGAN NEGARA (PERSERO) TBK CABANG PEMBANTU BUKITTINGGI
}

\author{
Fadli Alanshari, Doni Marlius \\ Akademi Keuangan dan Perbankan Padang \\ donimarlius@akbpstie.ac.id
}

\begin{abstract}
Home is one of the primary needs for humans, in this era it is difficult to build houses directly, especially in big cities. The price of land and the price of building materials that have been reduced when they are increasing and not in accordance with the average salary earned makes it difficult for residents to set up a house. Population growth from year to year is increasingly crowded, this encourages developers to compete to develop their businesses in the housing sector. Because everyone definitely needs a home. The KPR procedure is a clerical activity step, usually involving several people in one department or more, which is made to ensure uniform handling of a company's transactions that occur repeatedly. The types of mortgages consist of 2 types, namely subsidized housing loans and nonsubsidized housing loans. PT. BANK TABUNGAN NEGARA (1968) was shaky within the scope of public fund raising through savings, so since 1974 the State Savings Bank added its task of establishing KPR services and for the first time KPR distribution took place on December 10, 1976, therefore December 10 was celebrated as a day KPR for BTN.
\end{abstract}

Keywords : KPR Procedure, KPR distribution, KPR service.

\section{PENDAHULUAN}

Rumah adalah salah satu kebutuhan primer bagi manusia, di era sekarang sulit kiranya untuk membangun rumah secara langsung terlebih di kota besar. Harga tanah dan harga bahan bangunan yang setip saat mengalami kenaikan dan tidak sesuai dengan rata-rata gaji yang diperoleh membuat warga sulit untuk memndirikan sebuah rumah. Pertambahan penduduk yang dari tahun ke tahun semakin padat, hal ini mendorong para developer berlomba-lomba untuk mengembangkan usahanya di bidang perumahan. Karena setiap orang pasti membutuhkan rumah tempat tinggal. Dengan kondisi perekonomian yang tidak stabil, para developer memutar otak untuk bisa menarik para konsumen dengan berbagai cara. Salah satu cara yaitu dengan membanggun rumah dengan harga terjangkau. Menurut Zefriyenni Ira, (2014) KPR atau Kredit Kepemilikan Rumah adalah merupakan salah satu jenis pelayanan kredit yang diberikan oleh bank kepada nasabah yang mengajukan kredit khusus untuk terpenuhinya kebutuhan dalam mendirikan rumah atau memperbaiki rumah. Pihak developer bekerja sama dengan pihak bank memudahkan masyarakat dalam mendapatan rumah yaitu 
dengan kredit kepemilikan rumah (KPR). Bank memiliki peranan yang sangat penting untuk menjunjung tinggi perekonomian rakyat, karena melalui bank unitunit yang memiliki kelebihan modal dapat di salurkan kepada masyarakat melalui pinjam kredit. Disini terjadi simbiosis mutualisme antara kreditur dan debitur. Kredit Pemilikan Rumah (KPR) adalah kredit yang digunkan untuk membeli atau untuk kebutuhan konsumstif lainya dengan jaminan/agunan berupa Rumah. Walaupun kegunaanya sama, KPR berbeda dengan kredit konstruksi dan renovasi. Agunan yang di perlukan KPR adalah rumah yang akan di beli itu sendiri untuk KPR Pembelian. Sedangkan KPR Multiguna atau KPR Refinancing yang menjadi Agunan adalah Rumah yang sudah dimiliki. Menurut Nurul, (2012) Kredit diberikan atas dasar kepercayaan sehingga pemberian kredit adalah pemberian kepercayaan. Hal ini berarti bahwa prestasi yang diberikan benar-benar diyakini dapat dikembalikan oleh penerima kredit sesuai dengan waktu dan syarat-syarat yang telah ditentukan bersama. Menurut pasal 8 UU No. 7 tahun 1992 dalam memberikan pinjaman, perusahaan mampu meyakini atas kemampuan dan kesanggupan debitur dalam melunasi hutangnya sesuai yang disepakati. Dari ketentuan tersebut dapat di simpulkan bahwa bank harus hati-hati dalam memberikan kredit pada calon debiturnya, untuk meminimalkan risiko kerugian dari pemberian kredit, maka bank dalam melaksanakan tugas harus selalu berpedoman pada kebijakan dan prosedur penerapan manajeman risiko yang ditetapkan dan dilandaskan pada prinsip kehati-hatian atau prudential principal.

Salah satu bank yang beroperasi di Sumatera Barat khususnya Bukittinggi yaitu PT. Bank Tabungan Negara (Persero) cabang Bukittinggi adalah salah satu bank yang bekerja sama dengan pihak devoloper untuk memudahkan kepada calon debitur dalam pemberian kredit kepemilikan rumah. PT. Bank Tabungan Negara selama ini dikenal masyarakat dengan produk kredit kepemilikan rumah. PT. Bank Tabungan Negara memberikan prosedur yang mudah, bunga yang rendah dan angsuran yang terjangkau dalam kredit kepemilikan rumah. Hal ini terbukti dengan penghargaan yang diterima oleh PT. Bank Tabungan Negara (Persero) karena prestasinya dalam pemberian produk kredit pemilikan rumah.Salah satu produk Kredit Pemil ikan Rumah (KPR) di PT. Bank Tabungan Negara (persero) yaitu KPR Subsidi. KPR Subsidi adalah yang mempunyai tipe rumah maksimal dengan harga jual maksimal Rp 150.000.000. KPR lebih di minati oleh masyarakat karena harga jual rumah dan suku bunga yang rendah. Dalam pelaksanaannya, KPR mempunyai suatu masalah yaitu timbulnya penunggakan pembayaran anggsuran yang dapat menyebabkan kredit macet. Hal ini disebabkan oleh faktor intern dan faktor ekstern, faktor intern yaitu pihak bank dan debitur, sedangkan faktor ekstern yaitu lingkungan.

\section{Perumusan Masalah}

Berdasarkan latar belakang diatas maka perumusan masalah dalam penelitian ini adalah: Bagaimana prosedur pemberian kredit (KPR) pada PT. Bank Tabungan Negara (Persero) Tbk Cabang Pembantu Bukittinggi. 


\section{Tujuan Penelitian Dan Manfaat Penelitian Tujuan Penelitian}

Adapun tujuan dari penelitian ini adalah untuk mengetahui bagaimana prosedur pemberian kredit KPR pada PT. Bank Tabungan Negara (Persero) Tbk Cabang Pembantu Bukittinggi.

\section{Manfaat Penelitian}

a. Bagi Penulis merupakan alat untuk mengembangkan ilmu pengetahuan yang penulis dapatkan selama berada di bangku kuliah dan memperluas ilmu pengetahuan.

b. Bagi bank penelitian ini dapat dijadikan sebagai suatu bukti yang mendukung dalam mengetahui mengenai pengendalian kredit dalam upaya menciptakan bank yang sehat dan dapat juga sebagai bahan kajian lainnya. Dan terakhir penelitian ini juga berguna bagi pihak lain yang tidak terlibat langsung dalam penelitian. Penelitian ini dapat menambah pengetahuan dan dapat dijadikan sebagai referensi untuk melakukan penelitian yang lain.

\section{METODE PENELITIAN}

Dalam pengumpulan data dan bahan untuk melakukan penelitian ini digunakan metode-metode pengumpulan data dan metode analisa data, sebagai berikut:

a. $\quad$ Riset Lapangan ( Field Research )

Peninjauan langsung ke objek penelitian yang dipilih untuk meneliti hasil data primer. Penelitian langsung ke lapangan ini akan dapat membantu penulis untuk melengkapi data-data yang diperlukan.

b. Riset Perpustakaan ( Library Research)

Penelitian yang dilakukan ke perpustakaan berupa buku-buku ilmiah dan tulisan-tulisan yang berhubungan dengan pembahasan dilakukan.

\section{Metode Analisa Data}

Dalam menganalisa data, penulis menggunakan analisa data kualitatif. Data kualitatif merupakan data informasi yang berbentuk kalimat verbal bukan berupa simbol angka atau bilangan, maka dari itu dengan metode ini penulis akan mencoba memberikan fakta-fakta atau kenyataan yang dialami dengan teori-teori yang ada.

\section{HASIL DAN PEMBAHASAN}

\section{Landasan Teori}

Bank

Menurut Albertus, (2017) Bank berupa lembaga usaha keuangan pasa umumnya didirikan berdasarkan persetujuan dari perusahaan untuk menerima simpanan uang serta pinjaman uang karena dapat menerbitkan surat hutang. Serta menurut Undang-Undang Nomor 10 Tahun 1998 Tentang Perbankan, yang di 
maksud dengan bank adalah badan usaha yang menghimpun dana dari masyarakat dalam bentuk simpan dan menyalurkannya kepada masyarakat dalam bentuk kredit dan bentuk-bentuk lainya dalam meningkatkan kehidupan rakyat banyak. Menurut bank berupa lembaga keuangan yang kegiatan utamanya menghimpun dana dari masyarakat dan menyalurkanya kembali dana tersebut ke masyarakat serta memberikan jasa lainnya.

\section{Jenis-Jenis Bank}

Menurut Maikel, (2015) berdasarkan jenis lembaga usaha keuangan yang terdiri dua jenis yaitu bank Umun dan Bank Perkreditan Rakyat (BPR). Bank umum adalah lembaga usaha keuangan dapat melaksanakan aktivitas usaha secara konvensional berdasarkan syariah dalam kegiatannya menerim jasa melalui pembayaran, BPR adalah suatu lembaga keuangan dalam melaksanakan kegiatan usahanya secara umum berdasarkan syariah dalam kegiatannya tidak dapat menerima pelayanan jasa. Lembaga keuangan terdiri dari lembaga keuangan pemerintah, lembaga keuangan swasta nasional devisa, lembaga keuangan swasta nasional non devisa serta lembaga keuangan asing,.

Jenis Bank dilihat dari segi kepemilikan adalah sebagai berikut:

1) Lembaga keuangan milik pemerintah

Dimana baiknya surat pendirian perusahaan maupun modal yang dimiliki pemerintah secara pribadi.

2) Lembaga keuangan milikswasta nasional.

Lembaga keuanagan yang dilimiliki oleh swasta nasional serta surat pendirian perusahaan. Dan begitu pula pembagiankeuntungan.

Dari segi status pembagian lembaga keuangan dapat dilihat berdasarkan kedudukan serta status lembaga keuangan tersebut. Dalam kegiatan jenis lembaga keuangan dapat dilihat dari segi status yang terdiri dari dua macam yaitu:

1) Lembaga keuangan devisa

Lembaga keuangan yang berstatus devisa atau lembaga keuangan devisa yang dapat melaksanakan pembayaran keluar negeri serta berhubungan dengan mata uang asing.

2) Lembaga keuangan non devisa

Kebalikan dari lembaga keuangan devisa, dimana pembayaran yang dilakukan dalam satu negara.

\section{Fungsi Bank}

Menurut Adli, (2012) Bank sebagai sebuah lembaga keuangan tentu memiliki fungsi seperti halnya lembaga lembaga lain. Fungsi bank dalam perekonomian suatu Negara diklasifikasikan sebagai berikut :Fungsi bank Sebagai Agent of Trust Artinya bahwa aktivitas bank sebagai financial intermediary menjalankan fungsinya atas dasar kepercayaan yang diterima oleh bank dari masyarakat kepercayaan masyarakat yang diberikan berupa amanat agar bank mengelola dan mengamankan dana yang disimpan masyarakat di bank tersebut. Fungsi bank sebagai Agent of Trust ini tentu tidak terlepas dari prinsip saling menguntungkan bagi kedua belah pihak. Fungsi bank Sebagai Agent of development Guna mewujudkan pembangunan dan kesejahteraan dalam perekonomian, bank 
dianggap sebagai lembaga yang cukup berperan signifikan. Hal ini dikarenakan aktivitas bank sebagai financial intermediary dapat mempertemukan sektor riil dan sektor moneter untuk berinteraksi. Pada umumnya peredaran uang dalam perekonomian terjadi melalui lembaga keuangan sehingga interaksi sektor riil dan sektor moneter diharapkan berjalan dengan baik demi mendukung proses pembangunan. Fungsi Bank sebagai Agent of service Lembaga keuangan merupakan sebagai lembaga yang bergerak dibidang jasa yang lebih beragam, dengan kata lain aktivitas perbankan tidak hanya terbatas dalam hal menghimpun dana dan menyalurkan dana ditengah masyarakat.

\section{Pengertian Kredit}

Menurut Fitri, (2014) Kredit adalah sesuatu yang dibutuhkan oleh masyarakat guna mendorong dan melancarkan aktivitas perdagangan, baik dalam bidang memproduksi barang maupun jasa dan juga untuk meningkatkan atau memenuhi kebutuhan konsumsi masyarakat. Berdasarkan pengertian tersebut dapat di tarik kesimpulan bahwa kredit dapat berupa uang atau tagihan yang nilainya diukur dengan uang, contohnya bank membiayai kredit dalam pembelian ruamh. Pihak bank sebagai kreditur sementara nasabah penerima kredit (debitur).

\section{Unsur Kredit}

Menurut Dewi, (2013) Dalam pemberian kredit salah satu unsur yang paling penting adalah kesepakatan antara pihak bank dengan kreditur dan nasabah sebagai debitur. Berdasarakan hal tersebut dapat di simpulkan unsur-unsur yang terkandung dalam kredit adalah:

1. Kepercayaan.

2. Kesepakatan

3. Jangka waktu

4. Risiko

5. Balas jasa

\section{Fungsi Kredit}

Kredit di awal perkembangan fungsinya untuk merangsang kedua belah pihak untuk saling menolong dengan tujuan pencapain kebutuhan, baik itu dalam bidang usaha atau kebutuhan sehari-hari. Macam-macam fungsi kredit adalah:

1. Kredit dapat meningkatkan daya guna uang dan barang.

2. Kredit dapat meningkatkan peredaran dan lalu lintas uang.

3. Kredit sebagai alat stabilitas ekonomi.

4. Kredit sebagai jembetan meningkatkan pendapatan nasional.

5. Kredit juga sebagai alat hubungan ekonomi internasioal.

\section{Jenis-Jenis Kredit}

Menurut Andreani, (2013) Sebelum krdit dikucurkan bank terlebih dalu menilai kelayakan kredit yang diajukan oleh nasabah, kelayakan ini meliputi berbagai aspek penilain. Penerima kredit akan dikenakan bunga kredit yang 
besarnya tergantung dari bank yang menyalurkanya. Secara umum jenis-jenis kredit yang ditawarkan adalah:

1. Kredit Investasi adalah merupakan kredit yang diberikan kepada pengusaha atau penanaman modal.

2. Kredit Modal Kerja adalah kredit yang digunakan sebagai modal kerja dan berjangka pendek tidak lebih dari 1 (satu) tahun.

3. Kredit Perdagangan adalah kredit yang diberikan kepada para pedangang dalam rangka mempelancar kegiatan perdagangnya.

4. Kredit Produktif adalah kredit diberikan untuk diusahakan kembali sehingga pengambalian kredit diharapkan dari hasil usaha yang dibiayai.

5. Kredit Profesi adalah kredit yang diberikan kepada para kalangan profesional seperti dosen, dokter, atau pengacara.

\section{Pengertian Prosedur KPR}

Menurut Ira, (2015) Prosedur KPR ialah suatu langkah kegiatan yang klerikal, biasanya melibatkan beberapa orang dalam satu departemen atau lebih, yang dibuat untuk menjamin penanganan secara seragam transaksi suatu perusahaan yang terjadi secara berulang-ulang.

\section{Jenis-Jenis KPR KPR BTN Bersubsidi}

Program untuk pemilikan rumah dari Kementerian Pekerjaan Umum dan Perumahan Rakyat Republik Indonesia yang ditujukan bagi Masyarakat yang mempunyai penghasilan Rendah (MBR) dengan suku bunga rendah yaitu Suku bunga $5,00 \%$ fixed sepanjang jangka waktu kredit dan cicilan ringan untuk pembelian rumah sejahtera tapak dan rumah sejahtera susun. Dalam jangka waktu hingga 20 tahun dan Subsidi bantuan uang muka sebesar Rp. 4.000.000 (khusus rumah tapak)

\section{Syarat dan Ketentuan}

a. WNI umur 21 tahun atau sudah menikah

b. Usia pemohon tidak lebih dari 65 tahun pada saat pinjaman jatuh tempo. Khusus peserta ASABRI yang mendapatkan rekomendasi dari YKPP, usia pemohon tidak melebihi 80 tahun pada saat pinjaman jatuh tempo

c. Pemohon maupun pasangan (suami/isteri) tidak mempunyai tempat tinggal dan belum pernah menerima bantuan pemerintah untuk pemilikan rumah. Tidak termasuk untuk TNI/Polri/PNS yang pindah tugas

d. Gaji/penghasilan pokok tidak melebihi:

1) Rp4juta untuk Rumah Sejahtera Tapak

2) Rp7juta untuk Rumah Sejahtera Susun

e. Memiliki e-KTP dan terdaftar di Dukcapil

f. Memiliki NPWP dan SPT Tahunan PPh orang pribadi sesuai perundang-undangan yang berlaku 
g. Pengembang wajib terdaftar di Kementerian PUPR

h. Spesifikasi rumah sesuai dengan peraturan pemerintah

\section{Persyaratan Umum}

a) Mengisi formulir permohonan KPR

b) Foto copy KTP suami/istri yang masih berlaku

c) Foto copy KK

d) Foto copy surat nikah

e) Foto copy tabungan BTN

f) Pas foto suami/istri warna $3 \times 4$ sebanyak 1 lembar

g) NPWP permohon

h) Foto copy sertifikat

i) Foto copy IMB

j) Pembayaran PBB yang masih berjalan

k) Formulir kementrian pekerjaa umum dan perumahan warga

\section{Persyaratan Khusus}

1. Bagi Pegawai Negeri Sipil

a) Foto copy perincian gaji/slip gaji dan amprah gaji erakhir pemohon 2 bulan terakhir

b) Kuasa pemotongan gaji yang di tanda tangani bendahara gaji dan di ketahui pimpinan instansi

c) Foto copy SK trakhir, TASPEN atau keterangan instansi lainnya

d) Rekening koran gaji minimal 6 bulan terakhir

2. Bagi Karyawan Swasta

a) Foto copy perincian gaji/slip gaji

b) Kuasa pemotongan gaji yang di tanda tangani bendahara gaji dan diketahui pimpinan instansi

c) Foto copy surat keputusan pengangkatan

d) Surat keterangan kerja dari perusahaan

e) Rekening koran gaji minimal 6 bulan terakhir

3. Bagi Wiraswasta

a) Foto copy SIUP/SITU/AKTA CV/ NPWP perusahaan jika ada perusahaan

b) Laporan jual beli dan usaha

c) Data pendukung lain (seperti fotocopy BPKB, bukti sewa toko dll)

d) Foto copy rekening bak lain 6 bulan terakhir

e) Foto copy pembukuan 6 bulan terakhir dan bon penjualan dan pembelian.

Setelah semua data terpenuhi dan pihak bank akan memprosess pengajuan kredit KPR, prosedur yang selanjutnya dilakukan oleh pihak bank:

a. Pihak bank akan melakukan BI chaking

Ini merupakan pengecekan terhadap pemohon apakah ada pemohon tersangkut pinjaman atau yang berhubungan dengan bank maupun berbentuk leasing, koperasi atau yang lainnya. 
b. Wawancara

Wawancara merupakan pencarian informasi mengenai pemohon debitur, mengkonfirmasi bagaimana kehidupan mereka dalam bentuk ekonomi, pekerjaan mereka, peghasilan mereka, tanggungan mereka, dan melakukan penjelasan bagaimana perumahan subsidi KPR tersebut.

c. Laporan OTS (On The Spot)

Laporan OTS ini merupakan laporan yang di buat oleh pihak bank setelah mereka lakukan wawancara terhadap debitur dan setelah melakukan survei lapangan terhadap pemohon, dalam melakukan ots ini pihak bank akan membuat laporan tersebut akan di kirim kepada pimpinan setempat.

d. Laporan LPA (Laporan Pemeriksaan Akhir)

Setelah di setujui nya lapoan OTS maka pihak bank akan membuat lapoan LPA ini pihak bank akan merekomendasikan laporan ini kepada analis, analis lah yang akan memproses atau menindak lanjuti lapran ini sebelum pihak bank menyetujui kredit tersebut.

e. Kertas Kerja Analis

Dalam memubuat laporan kertas kerja analis disii pihak bank akan mmbawa seora akuntanuntuk menilai hasil dari lapran LPA da hasil OTS, dari hasil keputusan analislah pihak bank baru bisa memutuskan apakah kredit pemohon di setuju atau tidak, kalau semua sudah disetujui oleh pihak bank maka developer akan memproses para nasabah.

Itulah prosedur dalam pengajuan KPR subsidi pada PT Bank Tabungan Negara (persero) Tbk cabang pembantu Bukitinggi, sehingga dengan prosedur yang begitu rinci dan efektif membuat orang tidak bisa mengecoh dalam pemalsuan data atau lain sebagainya

\section{KPR BTN Non Subsidi (Platinum)}

Program KPR Non-subsidi (KPR Reguler) dari BTN dimana besaran pinjaman maupun suku bunga ditentukan berdasarkan kebijakan bank.

\section{Keunggulan KPR BTN Platinum}

Berikut ini adalah beberapa keunggulan dari produk KPR BTN Platinum:

1) Suku bunga kompetitif

2) Periode fixed sampai dengan 5 tahun sehingga nasabah bisa menikmati cicilan dengan bunga tetap yang ringan selama 5 tahun berturut-turut

3) Proses pengajuan cepat dan mudah

4) Jangka waktu cicilan yang telah ditentukan

5) Diberikan asuransi jiwa, asuransi kebakaran, dan gempa bumi

6) Bekerja sama dengan jaringan developer perumahan yang luas di seluruh wilayah Indonesia 


\section{Jenis Properti yang dapat Dibeli melalui KPR BTN Platinum}
1) Rumah
2) Apartemen
3) Ruko
4) Rukan
5) Office Space

\section{Pengajuan KPR BTN Platinum} perhatikan :

1) Pilih Properti yang akan diajukan atau dibeli (Rumah, Apartemen, Ruko/Rukan, Office Space).

2) Simulasi KPR untuk mengukur kemampuan cicilan

3) Tentukan bank penyedia layanan KPR.

4) Isi form pemesanan.

5) Bayar booking fee.

6) Pelunasan uang muka.

7) Isi form pengajuan kredit dan juga siapkan dokumen-dokumen yang dibutuhkan.

8) Analisa permohonan kredit.

9) Bank melakukan peninjauan kelapangan.

10) Akad kredit disetujui, siapkan biaya KPR dan administrasi. Melakukan akad kredit di depan notaris.

11) Bayar cicilan tiap bulan.

\section{SIMPULAN}

Berdasarkan hasil penelitian, dapat di simpulkan sebagai berikut:

1. Bank Tabungan Negara merupakan bank pemerintah yang memiliki peran yang cukup besar dalam menigkatkan perekonomian masyarakat khususnya dalam bidang papan (Perumahan). Bank BTN merupakan bank no 5 pemberian kredit perbankan terbesar dalam dunia perbankan. Salah satunya pada Bank Tabungan Negara (Persero) Tbk Cabang Pembantu Bukittinggi yang telah banyak membiayai proses pembangunan perumahan di sekitar Bukittinggi. PT. BTN (persero) Tbk telah memberikan konstribusi yang besar bagi masyarakat Bukittinggidengan segala pelayanannya yang terbaik dari segi pendanaan dan perkreditan.

2. Langkah-langkah pemberian pinjaman pada PT. BankTabungan Negara (persero) Tbk Cabang pembantu Bukittinggi mempermudah masyarakat untuk mendapatkan pembiayaan rumah dengan bunga yang rendah dan melakukan kerja sama dengan berbagai developer perumahan diberbagai wilayah sekitar Bukittinggi.

3. Mekanisme KPR pada BTN Cabang pembantu Bukittinggi mulai dari mengajukan permohonan kredit, vertifikasi, wawancara, analisa, persetujuan, akad, dan realisasi bagi masyarakat cukup jelas dan memudahkan dalam mendapatkan kredit pemilikan rumahnya dengan syarat dan ketentuan yang mudah di pahami. 


\section{SARAN}

Berdasarkan kesimpulan penelitian, maka penulis memberikan saran:

1. Bank Tabungan Negara (persero) Tbk sebagai bank yang cukup dikenal oleh masyarakat akan lebih di kenal masyarakat dengan menambah promosi kepada masyarakat melalui media internet, elektronik, ataupun media cetak. Apabila produk makin di kenal masyarakat, maka tingkat penjualan produk juga mangkin meningkat.

2. Dalam menyalurkan KPR sejahtera PT. BTN (persero) Tbk telah menyalurkan pada pihak yang tepat, yaitu masyarakat yang berpanghasilan rendah di bawah Rp. 2.500.000 dan masih produktif untuk menghindari keterlambatan angsuran akan tetapi, alangkah baiknya tetap memperhatikan prinsip kehati-hatian.

3. Dalam pelayanan terhadap nasabah hendaknya pihak Bank Tabungan Negara (persero) Tbk Cabang Pembantu Bukittinggi lebih memperhatikan pelayanan yang sepenuh hati dan tulus sesuai prisip $3 \mathrm{~A}$ yaitu Attitude, attention, dan action sebagai wujud pelayanan prima.

\section{DAFTAR PUSTAKA}

Adli, N. (2012). Studi Tentang Keputusan Nasabah Dalam Menabung Di Bank Sumut Cabang Usu Medan Metode Analytical Hierarchy Process (AHP). Ekonomi Dan Keuangan, 1(1).

Albertus, Y. (2017). Pelaksanaan Pengambilan Jaminan Kredit Oleh Pihak Ketiga Karena Debitur Tidak Diketahui Keberdayaanya di PT. Bank Tabungan Negara (Persero) Tbk Kantor Cabang Yogyakarta. Jurnal Ekonomi Dan Bisnis, 1, 1-13.

Andreani, C. (2013). Pengaruh Spread Tingkat Suku Bunga dan Rasio Keuangan Terhadap Penyaluran Kredit UMKM Pada Bank Umum di Indonesia. Jurnal Wira Ekonomi Mikroskil, 3(1), 11-20. https://doi.org/10.1017/CBO9781107415324.004

Dewi, A. (2013). Peranan Kredit Usaha Rakyat (KUR) Bagi Pengembangan UMKM Di Kota Medan (Studi Kasus Bank BRI). Jurnal Ekonomi Dan Kruangan, 1(3), 105-116.

Fitri, K. (2014). Evaluasi Sistem Dan Prosedur Penyaluran Kredit Konsumtif Dalam Upaya Mendukung Pengendalian Intern Pada Koperasi (Studi Kasus Pada Koperasi Karyawan Primkoppos Kota Malang). Jurnal Administrasi Bisnis $\quad(J A B), \quad 11(1), \quad 1-10 . \quad$ Retrieved from administrasibisnis.studentjournal.ub.ac.id

F Susanti, W Ekazaputri (2018). Service Performance Dan Kepuasan Sebagai Moderating Variabel Terhadap Loyalitas Nasabah Pada PT BPR Labuh Gunung Payakumbuh Jurnal Benefita: Ekonomi Pembangunan, Manajemen, Bisnis Dan Akuntansi, 3(3), 433-444. https:// doi : 10.22216/jbe.v3i3.3472

Ira, Y. (2015). Analisis Prosedur Pemberian Kredit Modal Kerja Dalam Usaha Mengantisipasi Kredit Bermasalah (Studi Pada PT. Bank Rakyat Indonesia (Persero) Tbk Cabang Jombang). Jurnal Administrasi Bisnis (JAB), 26(2), 1- 
7.

Marlius, D. (2017). Loyalitas nasabah bank nagari syariah cabang bukittinggi dilihat dari kualitas pelayanan. Journal Pundi, 1(3), 237-250. https://doi.org/10.31575/jp.v1i3.60

Maikel, O. (2015). Aanalisis Laporan Keuangan Untuk Menilai Kinerja Keuangan Pada PT. Bpr Citra Dumoga Manado. Jurnal EMBA, 3(1), 923-932. https://doi.org/ISSN 2303-1174

Nurul, F. (2012). Analisis Kebijakan Pemberian Kredit Dan Pengaruh Non Performing Loan Terhadap Loan To Deposit Ratio Pada PT. Bank Rakyat Indonesia (Persero), Tbk Cabang Rantau, Aceh Tamiang. ( Periode 20072011). Jurnal Ekonomi Dan Keuangan, 1(1), 88-101.

Yanti, B. (2012). Struktur Organisasi, Desain Kerja, Budaya Organisasi Dan Pengaruhnya Terhadap Produktivitas Karyawan Studi Kasus Padan Pt. Xx di Jakarta. Jurnal Liquidity, 1(2), 99-105.

Zefriyenni Ira. (2014). Kebijakan Pemberian Kredit Terhadap Penetapan Jumlah Kredit ( Studi Khasus Pada Ued-Sp Amanah Sejahtera Sungai Buluh Kecamatansingingi Hilirkabupaten Kuantan Singingi Propinsi Riau ). Jurnal Edik Informatika, 1 . 